\title{
Synthesis of $\mathrm{CuO}$ and $\mathrm{Cu}_{3} \mathrm{~N}$ Nanoparticles in and on Hollow Silica Spheres
}

\author{
Rupali Deshmukh $^{[a]}$ and Ulrich Schubert*[a]
}

Keywords: Nanoparticles / Hollow spheres / Mesoporous materials / Copper / Nitridation reactions / Nitrides

Copper oxide nanoparticles within hollow mesoporous silica spheres were prepared by binding/adsorbing $\mathrm{Cu}^{2+}$ or $\left[\mathrm{Cu}\left(\mathrm{NH}_{3}\right)_{4}\left(\mathrm{H}_{2} \mathrm{O}\right)_{2}\right]^{2+}$ ions on the surface of carbon spheres, followed by formation of a mesoporous silica shell by sol-gel processing and calcination in air. The $\mathrm{CuO}$ nanoparticles can subsequently be converted into $\mathrm{Cu}_{3} \mathrm{~N}$ nanoparticles by nitridation with ammonia. The effect of the different copper precursors, i.e. $\mathrm{Cu}^{2+}$ and $\left[\mathrm{Cu}\left(\mathrm{NH}_{3}\right)_{4}\left(\mathrm{H}_{2} \mathrm{O}\right)_{2}\right]^{2+}$, on the nanocomposites was studied. $\mathrm{CuO}$ nanoparticles on the outer surface of hollow silica spheres were obtained by thermal treatment of hollow $\mathrm{CuSiO}_{3}$ spheres in air. Nitridation of the $\mathrm{CuSiO}_{3}$ spheres with ammonia resulted in $\mathrm{Cu}_{3} \mathrm{~N} @ \mathrm{SiO}_{2}$ composites, with aggregated $\mathrm{Cu}_{3} \mathrm{~N}$ nanoparticles on hollow silica spheres.

\section{Introduction}

Nanostructured inorganic materials with spherical hollow morphologies have received much attention because of their characteristic shape, well-controlled size, high surface area, large void space, and ready tailorability and functionalization of both the hollow cores and the shells. ${ }^{[1,2]}$ Such systems have many potential applications owing to their unique and interesting properties. Porous metal oxide capsules have the potential for interesting applications because the pores provide a diffusion path to and from the hollow cores. Among them, mesoporous silica shells are of great importance because of their high surface area, tunable pore size, chemical inertness, and thermal/mechanical stability. ${ }^{[3]}$ Porous hollow spheres with encapsulated metal or metal oxide nanoparticles can be used as nanoreactors. ${ }^{[4-6]}$

In this paper we describe the synthesis of $\mathrm{CuO}$ or $\mathrm{Cu}_{3} \mathrm{~N}$ nanoparticles either within hollow mesoporous silica spheres or on their outer surface, in extension of our work on $\mathrm{Cu}_{3} \mathrm{~N}$ nanoparticles embedded in a silica matrix. ${ }^{[7]}$ $\mathrm{CuO}-$ silica and $\mathrm{Cu}_{3} \mathrm{~N}$-silica composite nanostructures were recently investigated for various applications such as catalysis, photocatalysis, corrosion resistance, and optics. ${ }^{[8]}$ The chemical inertness, high temperature stability, and biocompatibility are important features of silica, which makes them ideal ingredients of composite materials. The incorporation of nanoparticles within or on hollow silica spheres provides structurally new functional nanomaterials.

[a] Institute of Materials Chemistry,

Vienna University of Technology,

1060 Vienna, Austria

E-mail: Ulrich.Schubert@tuwien.ac.at

Homepage: http://www.imc.tuwien.ac.at/

Supporting information for this article is available on the WWW under http://dx.doi.org/10.1002/ejic.201201442

$r \mathrm{Re}$-use of this article is permitted in accordance with the Terms and Conditions set out at http://onlinelibrary.wiley.com/journal/ 10.1002/(ISSN)1099-0682c/homepage/2005_onlineopen.html

\section{Results and Discussion}

\section{$\mathrm{CuO}$ and $\mathrm{Cu}_{3} \mathrm{~N}$ Nanoparticles in Hollow Silica Spheres}

Hollow particles can be synthesized with the help of a sacrificial core template such as silica, carbon, or polystyrene spheres. Various types of metal oxide hollow spheres were obtained with carbon sphere templates. ${ }^{[9]}$ They are hydrophilic and inherently contain functional groups such as $-\mathrm{OH},-\mathrm{CHO},-\mathrm{COOH}$ on the surface, which can be used for binding metal ions without necessitating additional surface functionalization. After formation of the metal oxide shell, the carbon template is removed by thermal oxidation in air.

The synthesis protocol for the rattle-type mesoporous $\mathrm{Cu}_{3} \mathrm{~N} @ \mathrm{SiO}_{2}$ spheres described in this work is schematically shown in Figure 1 and consists of

1. adsorption of a copper(II) compound to the surface of $300 \mathrm{~nm}$ monodispersed carbon spheres (CS), which were prepared from an aqueous glucose solution according to Sun et al., ${ }^{[10]}$

2. generation of a silica shell on the copper-loaded CS by sol-gel processing in the presence of a surfactant as porogen,

3. calcination of the $\mathrm{Cu}^{\mathrm{II}} / \mathrm{CS} /$ silica composite spheres in air to remove the carbon core and the porogen, resulting in $\mathrm{CuO}$ nanoparticles within the hollow mesoporous silica spheres, and

4. conversion of the entrapped $\mathrm{CuO}$ nanoparticles to $\mathrm{Cu}_{3} \mathrm{~N}$ nanoparticles by ammonia nitridation.

A similar approach (steps 1-3) was already reported for the synthesis of hollow porous silica spheres containing $\mathrm{Pd}^{[5]}$ or $\mathrm{Fe}_{3} \mathrm{O}_{4}$ nanoparticles. ${ }^{[6]}$

In the work presented here, $\mathrm{Cu}^{2+}$ or $\left[\mathrm{Cu}\left(\mathrm{NH}_{3}\right)_{4}\left(\mathrm{H}_{2} \mathrm{O}\right)_{2}\right]^{2+}$ ions were adsorbed/bonded to the reactive functional groups on the CS particle surface. The copper-loaded car- 

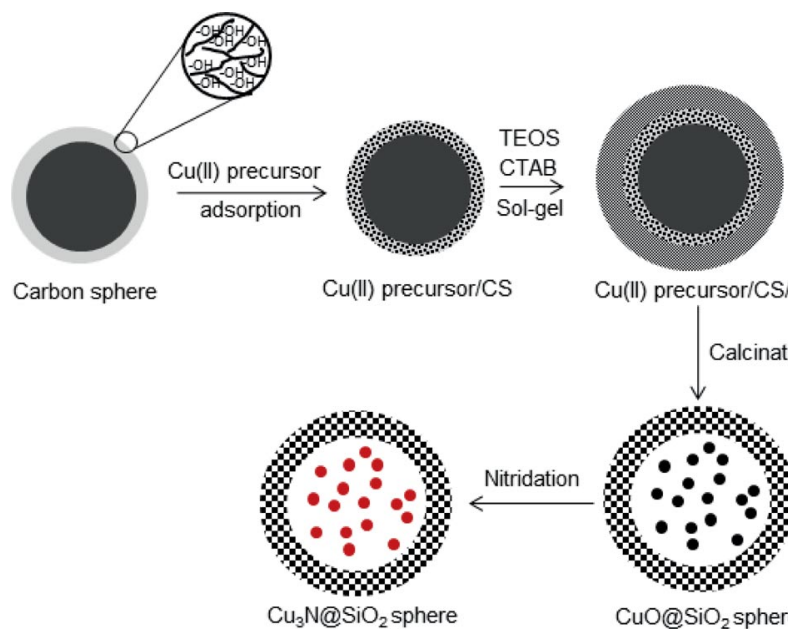

$\mathrm{Cu}(\mathrm{ll})$ precursor/CS/SiO Calcination

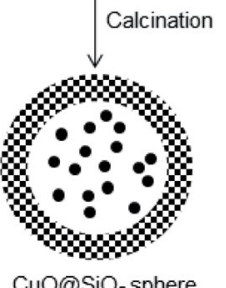

$\mathrm{CuO@SiO}{ }_{2}$ sphere

Figure 1. Schematic illustration of the preparation of $\mathrm{Cu}_{3} \mathrm{~N}$ nanoparticles inside hollow mesoporous silica spheres.

bon spheres were then coated with a silica layer by sol-gel processing of $\mathrm{Si}(\mathrm{OEt})_{4}$ (TEOS) in the presence of cetyltrimethylammonium bromide (CTAB). The surfactant has the role of a porogen; inter-particle porosity is created upon its thermal degradation. When the copper-loaded and silicacoated CS were heated in air, both the carbon core and the porogen were oxidatively removed. The (then porous) silica shell remained and $\mathrm{CuO}$ nanoparticles were formed within the hollow silica sphere.

Dispersion of the carbon spheres in an aqueous $\mathrm{Cu}\left(\mathrm{NO}_{3}\right)_{2}$ solution led to adsorption/binding of $\mathrm{Cu}^{2+}$ ions on the surface of the carbon spheres. TGA of the $\mathrm{Cu}^{2+}$ loaded and silica-coated $\mathrm{CS}$ [labeled $\mathrm{Cu}^{2+} / \mathrm{CS} / \mathrm{SiO}_{2}$ ] (Figure $\mathrm{S} 1$ ) showed that the oxidation of the carbon spheres and organic constituents is essentially finished at $400^{\circ} \mathrm{C}$, with some char formation. Char is removed by further heating to ca. $470{ }^{\circ} \mathrm{C}$. On the basis of the TGA analysis, the $\mathrm{Cu}^{2+} /$ $\mathrm{CS} / \mathrm{SiO}_{2}$ were calcined at $550{ }^{\circ} \mathrm{C}$ in air, and a black powder was obtained [labeled $\left.\mathrm{CuO} @ \mathrm{SiO}_{2}(\mathrm{~A})\right]$. The XRD pattern of $\mathrm{CuO} @ \mathrm{SiO}_{2}(\mathrm{~A})$ (Figure 2, a) revealed monoclinic $\mathrm{CuO}$ nanoparticles (JCPDS 41-0254). The broad hump at $<30^{\circ}$ is from the amorphous silica. The $\mathrm{CuO}$ crystallite size was $19 \mathrm{~nm}$ as calculated by Scherrer's equation. Nitridation of $\mathrm{CuO} @ \mathrm{SiO}_{2}(\mathrm{~A})$ at $300^{\circ} \mathrm{C}$ under an ammonia atmosphere

gave a brown product [labeled $\left.\mathrm{Cu}_{3} \mathrm{~N} @ \mathrm{SiO}_{2}(\mathrm{~A})\right]$, the XRD pattern of which corresponded to cubic $\mathrm{Cu}_{3} \mathrm{~N}$ (JCPDS-862283, Figure 2, b). The average crystallite size of $\mathrm{Cu}_{3} \mathrm{~N}$ was $17 \mathrm{~nm}$, i.e. the crystallite size was preserved upon nitridation.

The nitrogen adsorption isotherms of $\mathrm{CuO} @ \mathrm{SiO}_{2}(\mathrm{~A})$ and $\mathrm{Cu}_{3} \mathrm{~N} @ \mathrm{SiO}_{2}(\mathrm{~A})$ (Figure S2) are of type IV, which is characteristic of mesoporous materials, with some microand macroporosity (Table 1). $\mathrm{CuO} @ \mathrm{SiO}_{2}(\mathrm{~A})$ spheres have a high surface area, and the pore size distribution is centered at $2.5 \mathrm{~nm}$. The surface area and pore volume are slightly lower for $\mathrm{Cu}_{3} \mathrm{~N} @ \mathrm{SiO}_{2}(\mathrm{~A})$. This may be because of the basic conditions during nitridation, which might lead to restructuring of some mesopores/micropores.

Table 1. Surface and pore characteristics.

\begin{tabular}{lccc}
\hline Sample & $\begin{array}{c}\text { Specific surface } \\
\text { area }\left[\mathrm{m}^{2} / \mathrm{g}\right]\end{array}$ & $\begin{array}{c}\text { Pore diameter } \\
{[\mathrm{nm}]}\end{array}$ & $\begin{array}{c}\text { Pore volume } \\
{[\mathrm{cm} / \mathrm{g}]}\end{array}$ \\
\hline $\mathrm{CuO} @ \mathrm{SiO}_{2}(\mathrm{~A})$ & 953 & 2.5 & 0.78 \\
$\mathrm{Cu}$ N $@ \mathrm{SiO}_{2}(\mathrm{~A})$ & 671 & 2.3 & 0.53 \\
$\mathrm{CuO} @ \mathrm{SiO}_{2}(\mathrm{~B})$ & 747 & 2.6 & 0.70 \\
$\mathrm{Cu}$ N & 523 & 2.4 & 0.56 \\
\hline
\end{tabular}

The SEM image (Figure S3) of $\mathrm{Cu}_{3} \mathrm{~N} @ \mathrm{SiO}_{2}(\mathrm{~A})$ shows that the spherical morphology is retained after calcination and nitridation. According to the EDX spectrum (Figure S4), the copper loading was $4 \mathrm{wt} .-\%$. The STEM and TEM images of $\mathrm{Cu}_{3} \mathrm{~N} @ \mathrm{SiO}_{2}(\mathrm{~A})$ spheres (Figure 3) show that the $\mathrm{Cu}_{3} \mathrm{~N}$ nanoparticles are encapsulated in the hollow
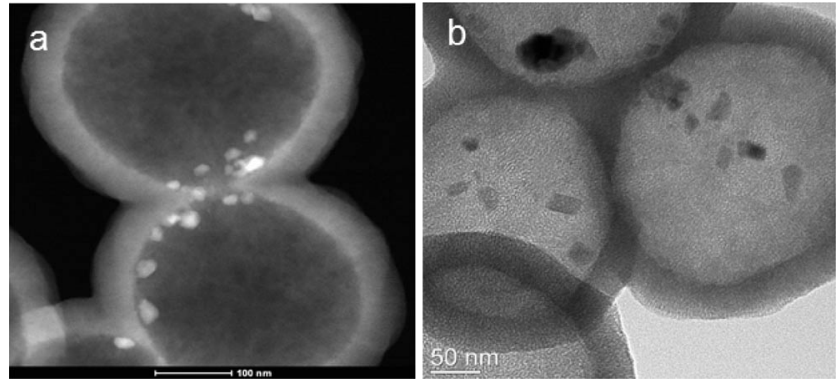

Figure 3. STEM (a) and TEM(b) images of $\mathrm{Cu}_{3} \mathrm{~N} @ \mathrm{SiO}_{2}(\mathrm{~A})$ spheres.
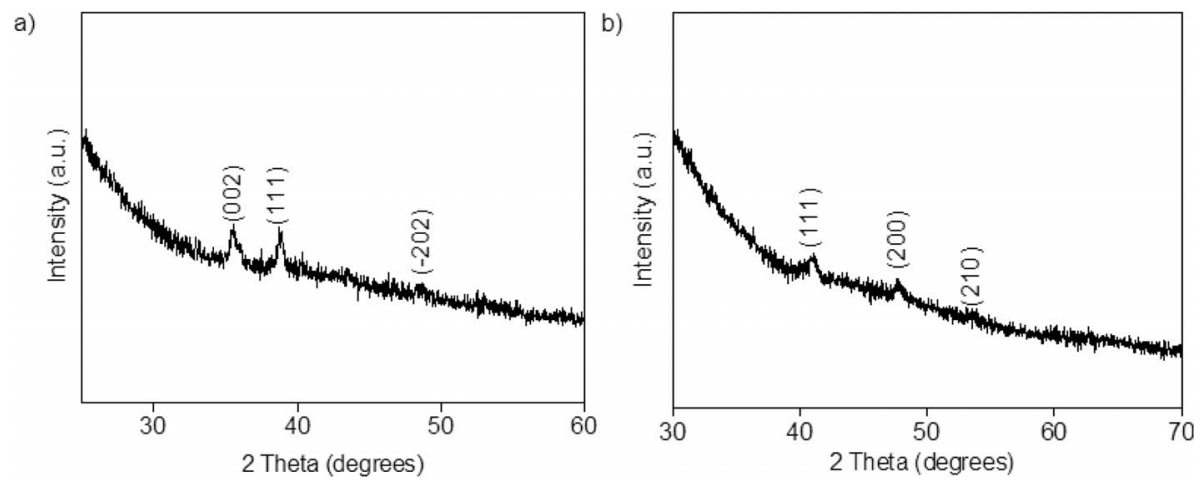

Figure 2.XRD patterns of $\mathrm{CuO} @ \mathrm{SiO}_{2}(\mathrm{~A})$ spheres (a) and $\mathrm{Cu}_{3} \mathrm{~N} @ \mathrm{SiO}_{2}(\mathrm{~A})$ spheres (b). 
mesoporous $\mathrm{SiO}_{2}$ spheres. As seen in the STEM image, the $\mathrm{Cu}_{3} \mathrm{~N}$ nanoparticles follow the shape of the sphere.

Although well-separated $\mathrm{Cu}_{3} \mathrm{~N}$ nanoparticles with diameters $<30 \mathrm{~nm}$ encapsulated in the hollow mesoporous silica spheres were obtained starting from $\mathrm{Cu}\left(\mathrm{NO}_{3}\right)_{2}$, the amount of $\mathrm{Cu}_{3} \mathrm{~N}$ nanoparticles per silica sphere was limited. Therefore, the first step of the synthesis protocol, i.e. loading of the CS with a copper compound, was modified and the copper complex $\left[\mathrm{Cu}\left(\mathrm{NH}_{3}\right)_{4}\left(\mathrm{H}_{2} \mathrm{O}\right)_{2}\right]^{2+}$ was employed instead of $\mathrm{Cu}\left(\mathrm{NO}_{3}\right)_{2}$. This modification is not just a change of the copper source, but also a change of the reaction conditions, because the employed aqueous $\left[\mathrm{Cu}\left(\mathrm{NH}_{3}\right)_{4}\right.$ $\left.\left(\mathrm{H}_{2} \mathrm{O}\right)_{2}\right]^{2+}$ solution is inherently basic. All subsequent steps were performed as described above.

TGA of $\left[\mathrm{Cu}\left(\mathrm{NH}_{3}\right)_{4}\left(\mathrm{H}_{2} \mathrm{O}\right)_{2}\right]^{2+} / \mathrm{CS} / \mathrm{SiO}_{2} \quad$ (Figure $\mathrm{S} 5$ ) showed that oxidation of the organic constituents and the CS occurs at somewhat lower temperatures. For this reason, calcination of the composite in air was carried out at a lower temperature, i.e. $500{ }^{\circ} \mathrm{C}$ for $2 \mathrm{~h}$. The obtained $\mathrm{CuO}$ nanoparticles in the hollow mesoporous $\mathrm{SiO}_{2}$ spheres $\left[\mathrm{CuO} @ \mathrm{SiO}_{2}(\mathrm{~B})\right]$ were converted to $\mathrm{Cu}_{3} \mathrm{~N}$ nanoparticles $\left[\mathrm{Cu}_{3} \mathrm{~N} @ \mathrm{SiO}_{2}(\mathrm{~B})\right]$ by nitridation at $350{ }^{\circ} \mathrm{C}$ for $2 \mathrm{~h}$ in ammonia. The crystallite sizes of $\mathrm{CuO}(22 \mathrm{~nm})$ and $\mathrm{Cu}_{3} \mathrm{~N}(15 \mathrm{~nm})$ were in the same range as the particle sizes obtained by the first route.

The nitrogen adsorption isotherm of $\mathrm{CuO} @ \mathrm{SiO}_{2}(\mathrm{~B})$ and $\mathrm{Cu}_{3} \mathrm{~N} @ \mathrm{SiO}_{2}(\mathrm{~B})$ (Figure $\mathrm{S} 6$ ) was again characteristic of mesoporous materials (type IV isotherm). The $\mathrm{CuO} @ \mathrm{SiO}_{2}(\mathrm{~B})$ spheres showed a surface area of $747 \mathrm{~cm}^{3} / \mathrm{g}$, and the pore size distribution showed a sharp maximum centered at $2.6 \mathrm{~nm}$. After nitridation the surface area was $523 \mathrm{~cm}^{3} / \mathrm{g}$, and the pore size distribution was centered at $2.4 \mathrm{~nm}$ (Table 1).

The SEM image of $\mathrm{CuO} @ \mathrm{SiO}_{2}(\mathrm{~B})$ (Figure S7) showed that the spherical morphology of the template was also retained. Some broken spheres confirmed the hollow morphology. According to the EDX spectrum (Figure S8), the copper loading was $24 \mathrm{wt} .-\%$, which is much higher than that for the particles obtained from $\mathrm{Cu}\left(\mathrm{NO}_{3}\right)_{2}$ as the copper precursor. The higher copper loading is also evidenced by the higher intensity of the reflections in the diffractograms of both $\mathrm{CuO}$ and $\mathrm{Cu}_{3} \mathrm{~N}$ (Figure 4).

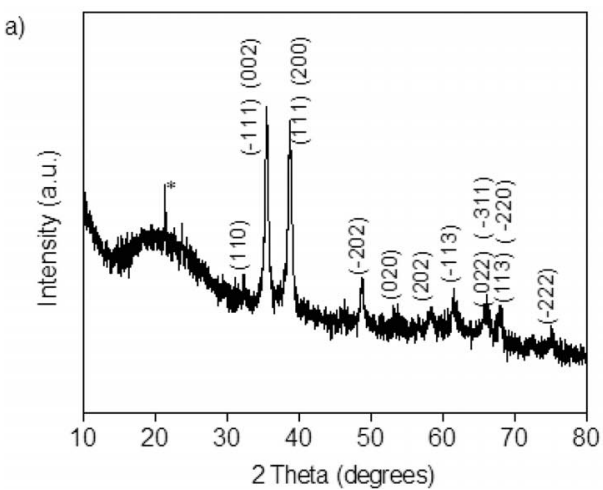

TEM images of $\mathrm{CuO} @ \mathrm{SiO}_{2}(\mathrm{~B})$ (Figure 5) and $\mathrm{Cu}_{3} \mathrm{~N} @ \mathrm{SiO}_{2}$ (B) spheres (Figure 6) clearly confirmed that the $\mathrm{CuO}$ nanoparticles are exclusively located inside the hollow mesoporous silica spheres and that the morphology was not changed upon nitridation. The $\mathrm{Cu}_{3} \mathrm{~N}$ particle size distribution appears to be broader than that of the $\mathrm{CuO}$ particles, or the $\mathrm{Cu}_{3} \mathrm{~N}$ particles are more agglomerated/aggregated. The thickness of the silica shell is around $40 \mathrm{~nm}$ in the present case; it could easily be tuned by changing the weight ratio of the carbon sphere to TEOS.
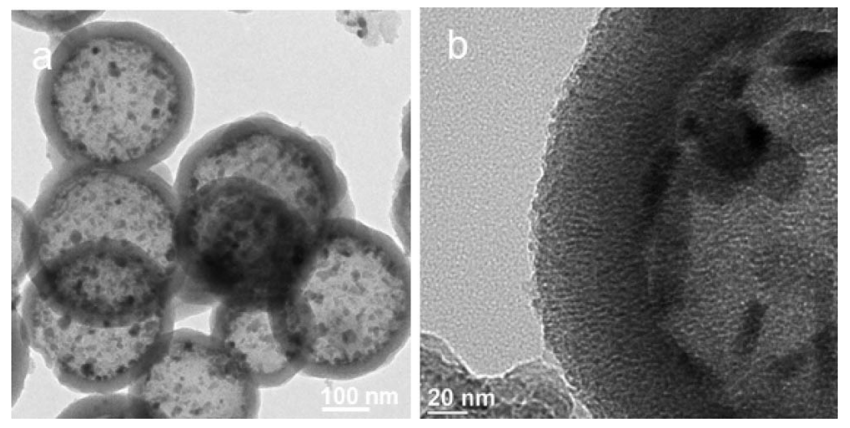

Figure 5. TEM images of $\mathrm{CuO} @ \mathrm{SiO}_{2}(\mathrm{~B})$ spheres.

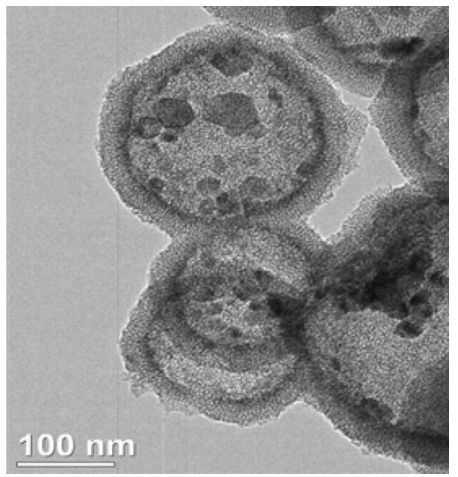

Figure 6. TEM image of $\mathrm{Cu}_{3} \mathrm{~N} @ \mathrm{SiO}_{2}(\mathrm{~B})$ spheres.

\section{$\mathrm{CuO}$ and $\mathrm{Cu}_{3} \mathrm{~N}$ Nanoparticles on Hollow Silica Spheres}

The possibility of chemically converting metal silicate nanostructures into new chemical entities offers many op-

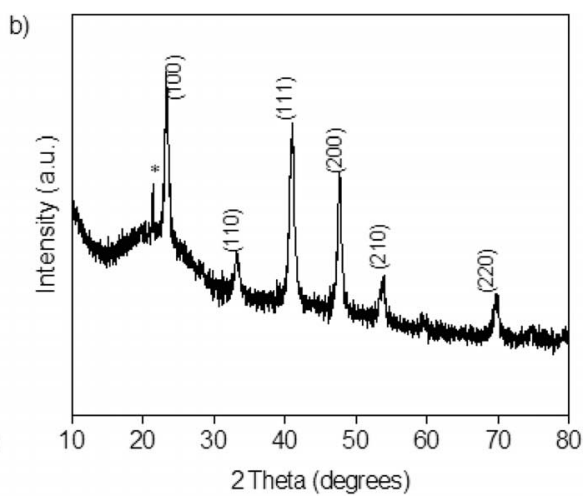

Figure 4. XRD pattern (* cristobalite) of $\mathrm{CuO} @ \mathrm{SiO}_{2}(\mathrm{~B})$ (a) and $\mathrm{Cu}_{3} \mathrm{~N} @ \mathrm{SiO}_{2}(\mathrm{~B})$ (b). 


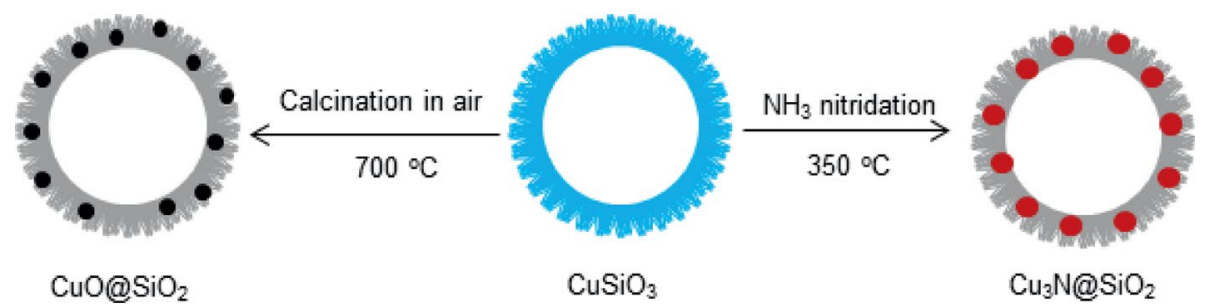

Figure 7. Synthesis of $\mathrm{CuO}$ on $\mathrm{SiO}_{2}$ and $\mathrm{Cu}_{3} \mathrm{~N}$ on $\mathrm{SiO}_{2}$ from $\mathrm{CuSiO}_{3}$.

tions for the synthesis of new functional materials. For example, Jin et al. reported the synthesis of nickel-hollow silica sphere composites by hydrogen reduction of $\mathrm{Ni}_{3} \mathrm{Si}_{2} \mathrm{O}_{5}(\mathrm{OH})_{4}$ at elevated temperatures. The hollow nanospheres exhibited high catalytic activity and good selectivity in acetone hydrogenation reactions. ${ }^{[11]}$

Hydrothermal treatment of Stöber silica spheres ${ }^{[12]}$ with copper nitrate under alkaline conditions at $140{ }^{\circ} \mathrm{C}$ results in the formation of hollow $\mathrm{CuSiO}_{3}$ spheres as reported by Wang et al. ${ }^{[13]}$ Synthesis of $\mathrm{CuO}$ and $\mathrm{Cu}_{3} \mathrm{~N}$ nanoparticles on the surface of hollow silica spheres (labeled " $\mathrm{CuO}$ on $\mathrm{SiO}_{2}$ " and " $\mathrm{Cu}_{3} \mathrm{~N}$ on $\mathrm{SiO}_{2}$ ") from the $\mathrm{CuSiO}_{3}$ spheres is schematically shown in Figure 7. Heat treatment in air at $700{ }^{\circ} \mathrm{C}$ led to the formation of $\mathrm{CuO}$ nanoparticles spread on the surface of the hollow silica spheres. $\mathrm{Cu}_{3} \mathrm{~N}$ nanoparticles on the hollow $\mathrm{SiO}_{2}$ spheres were obtained by reaction of the $\mathrm{CuSiO}_{3}$ spheres with ammonia at $350{ }^{\circ} \mathrm{C}$.

Figure 8 shows TEM images of the starting $\mathrm{CuSiO}_{3}$ hollow spheres, which are composed of nanocrystals (Figure S9). Special features are nanotubes (Figure 8, b), which are arranged vertically on the surface of the spheres and were assumed to also consist of $\mathrm{CuSiO}_{3} \cdot{ }^{[13]}$ Similar morphologies were also observed for other hollow spheres obtained by leaching processes. ${ }^{[14]}$
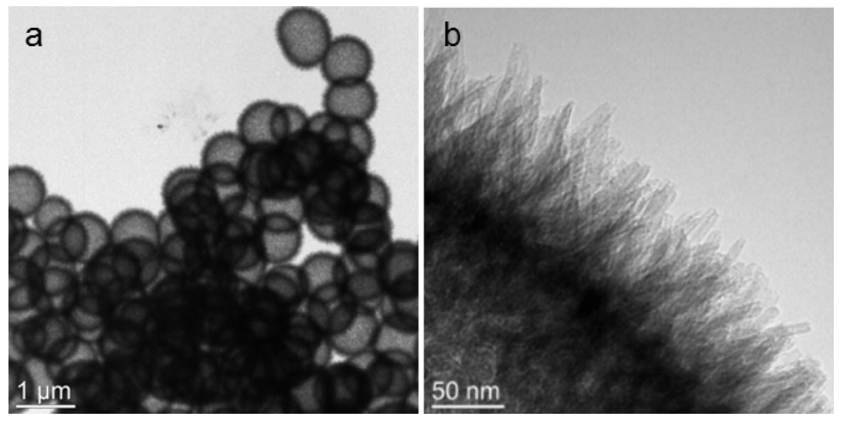

Figure 8. TEM images of the hollow $\mathrm{CuSiO}_{3}$ spheres.

Heat treatment of the blue hollow $\mathrm{CuSiO}_{3}$ spheres at $700{ }^{\circ} \mathrm{C}$ in air led to the formation of the black $\mathrm{CuO}$ on the $\mathrm{SiO}_{2}$ composite through disintegration of the copper silicate. Temperatures below $700{ }^{\circ} \mathrm{C}$ did not result in the formation of $\mathrm{CuO}$ nanoparticles. The XRD pattern is clear evidence for the formation of monoclinic $\mathrm{CuO}$ nanocrystals (Figure 9). The crystallite size of the $\mathrm{CuO}$ crystals was $10 \mathrm{~nm}$. The surface area and average pore size of $\mathrm{CuO}$ on $\mathrm{SiO}_{2}$ was $181 \mathrm{~m}^{2} / \mathrm{g}$ and $3 \mathrm{~nm}$, respectively (Figure S10). The much lower surface area, compared with $\mathrm{CuO} @ \mathrm{SiO}_{2}(\mathrm{~A})$ or
$\mathrm{CuO} @ \mathrm{SiO}_{2}(\mathrm{~B})$ (Table 1), is due to the different preparation method of the hollow silica spheres, where no template for mesopores, i.e. no surfactant, was involved.

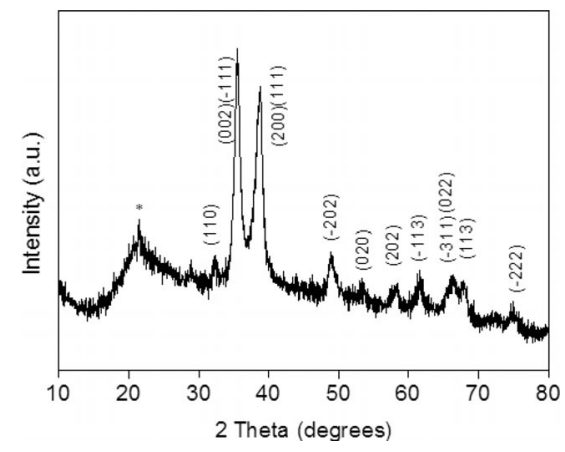

Figure 9. XRD pattern of $\mathrm{CuO}$ on $\mathrm{SiO}_{2}$ (* cristobalite).

TEM (Figure 10) images clearly show that the morphology of the $\mathrm{CuO}$ on $\mathrm{SiO}_{2}$ composite is almost the same as that of the starting $\mathrm{CuSiO}_{3}$. The high magnification TEM image revealed that $\mathrm{CuO}$ nanoparticles are spread on the shell of the hollow silica spheres.

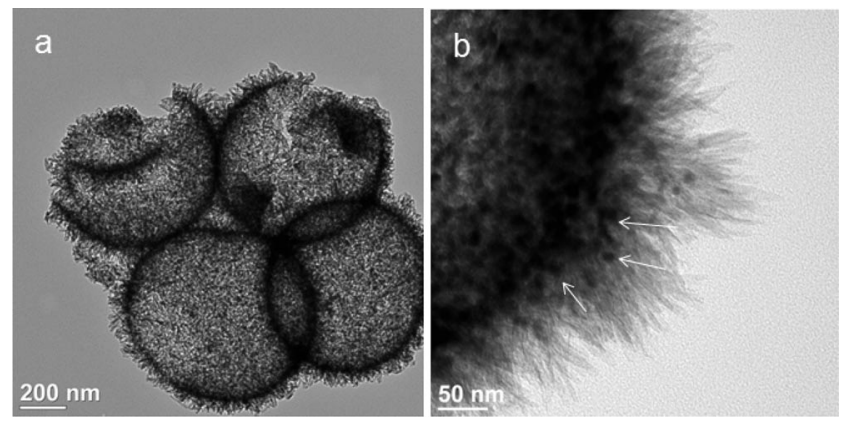

Figure 10. TEM images of $\mathrm{CuO}$ on $\mathrm{SiO}_{2} \cdot \mathrm{CuO}$ nanoparticles are marked by arrows.

After the nitridation reaction of the hollow $\mathrm{CuSiO}_{3}$ spheres with ammonia at $350^{\circ} \mathrm{C}$ for $1 \mathrm{~h}$, hollow silica spheres with $\mathrm{Cu}_{3} \mathrm{~N}$ nanoparticles on the surface were produced without losing the hollow morphology of the $\mathrm{CuSiO}_{3}$ precursor. The nanotubes on the surface of the spheres were again retained. XRD analysis of the brown product (Figure 11) showed the presence of cubic $\mathrm{Cu}_{3} \mathrm{~N}$ nanocrystals and amorphous silica as well as complete conversion from $\mathrm{CuSiO}_{3}$ to $\mathrm{Cu}_{3} \mathrm{~N}$ on $\mathrm{SiO}_{2}$. The crystallite size of $\mathrm{Cu}_{3} \mathrm{~N}$ crystals was $31 \mathrm{~nm}$. The BET surface area was $159 \mathrm{~m}^{2} / \mathrm{g}$ and the pore size distribution from the adsorption branch of the isotherm was centered at 3-4 nm (Figure S11). 


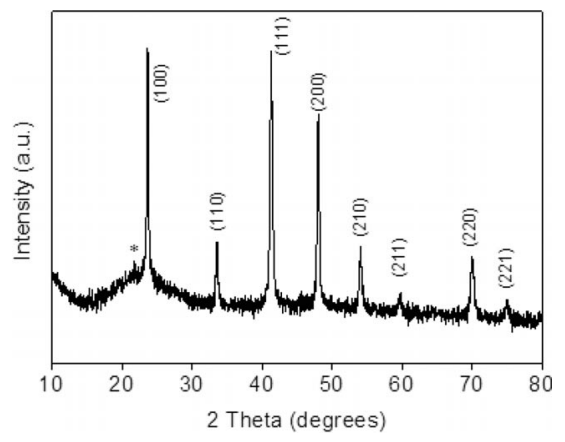

Figure 11. XRD pattern of $\mathrm{Cu}_{3} \mathrm{~N}$ on $\mathrm{SiO}_{2}$ (* cristobalite).

SEM (Figure S12) and TEM analysis (Figure 12) of the $\mathrm{Cu}_{3} \mathrm{~N}$ on $\mathrm{SiO}_{2}$ clearly showed $\mathrm{Cu}_{3} \mathrm{~N}$ nanoparticles on the surface of the hollow silica particles.

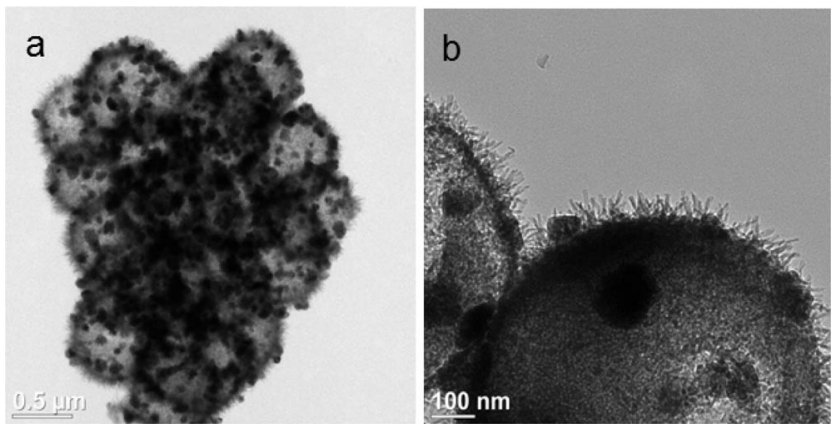

Figure 12. TEM images of $\mathrm{Cu}_{3} \mathrm{~N}$ on $\mathrm{SiO}_{2}$.

Both reactions showed that the copper ions of the copper silicate structure migrated to the surface of the silica spheres during heat treatment or nitridation to form $\mathrm{CuO}$ and $\mathrm{Cu}_{3} \mathrm{~N}$ nanoparticles, respectively. New morphologies of $\mathrm{CuO}$ on $\mathrm{SiO}_{2}$ and $\mathrm{Cu}_{3} \mathrm{~N}$ on $\mathrm{SiO}_{2}$ composites were thus synthesized from the $\mathrm{CuSiO}_{3}$ precursor. Although the temperature during nitridation was much lower than during thermal decomposition, the obtained $\mathrm{Cu}_{3} \mathrm{~N}$ nanoparticles were much larger than the $\mathrm{CuO}$ nanoparticles. Extraction of the $\mathrm{Cu}$ ions from the silicate network is apparently strongly favored when supported by a chemical reaction. Although a $\mathrm{Cu}_{3} \mathrm{~N}$ nanoparticle size of $31 \mathrm{~nm}$ was determined from the XRD experiment, the particles appear to be much larger in the TEM micrographs. This indicates that the larger particles observed by TEM are in fact composed of smaller nanoparticles.

An interesting side aspect is that the nanotubular structures on the surface of the hollow particles were preserved. The XRD pattern after thermal decomposition (Figure 9) or nitridation (Figure 11) did not indicate any residual $\mathrm{CuSiO}_{3}$ phase. The investigation of the composition of the nanotubular structures in the $\mathrm{CuO}$ on the $\mathrm{SiO}_{2}$ composites by electron microscopy failed because the nanotubes were easily deformed by the electron beam during the analysis. Although the chemical composition of the nanotubes could not be determined experimentally, the only reasonable possibility is that they consist of silica. One possibility is that the nanotubes originally consisted of $\mathrm{CuSiO}_{3}$, as postulated by Wang et al. ${ }^{[13]}$ and the copper ions were leached during the subsequent reactions. Another possibility is that the nanotubes consisted of pure silica from the very beginning.

\section{Conclusions}

A multistep protocol for the synthesis of $\mathrm{CuO}$ or $\mathrm{Cu}_{3} \mathrm{~N}$ nanoparticles within hollow mesoporous silica spheres was described, starting from carbon spheres as templates to which copper(II) precursors were adsorbed/bonded. This approach, which was previously proven successful for metal or metal oxide nanoparticles, ${ }^{[5,6]}$ was now extended to metal nitride nanoparticles. It is anticipated that this post-synthesis modification of metal oxide particles inside the hollow albeit porous capsule can be generalized to prepare other functional nanoparticles, such as other metal nitrides or chalcogenides, within hollow mesoporous silica spheres.

Variation of the copper precursor, i.e. $\mathrm{Cu}\left(\mathrm{NO}_{3}\right)_{2}$ vs. $\left[\mathrm{Cu}\left(\mathrm{NH}_{3}\right)_{4}\left(\mathrm{H}_{2} \mathrm{O}\right)_{2}\right]^{2+}$ (and/or the concomitant different reaction conditions) was found to affect the loading of the carbon spheres and thus the amount of $\mathrm{Cu}_{3} \mathrm{~N}$ nanoparticles per silica sphere. This allows controlling the $\mathrm{Cu}_{3} \mathrm{~N}$ proportion in the final materials. $\mathrm{Cu}\left(\mathrm{NO}_{3}\right)_{2}$ and $\left[\mathrm{Cu}\left(\mathrm{NH}_{3}\right)_{4}-\right.$ $\left.\left(\mathrm{H}_{2} \mathrm{O}\right)_{2}\right]^{2+}$ interact differently with the functional surface groups on the carbon spheres or the nature of these groups is changed by the more basic reaction conditions in the latter case.

The conversion of $\mathrm{CuSiO}_{3}$ to $\mathrm{CuO}$ on $\mathrm{SiO}_{2}$ and $\mathrm{Cu}_{3} \mathrm{~N}$ on $\mathrm{SiO}_{2}$ is a new observation. In each case the hollow sphere morphology of the starting $\mathrm{CuSiO}_{3}$ was well preserved. It is anticipated that this approach can also be applied to synthesize other metal oxide and metal nitride/silica hollow hybrid systems.

\section{Experimental Section}

Glucose and cetyltrimethylammonium bromide (CTAB) were purchased from Sigma Aldrich, $\mathrm{Cu}\left(\mathrm{NO}_{3}\right)_{2} \cdot 3 \mathrm{H}_{2} \mathrm{O} 99.5 \%$ and ethanol from Merck, aqueous ammonia (28-30 wt.- $\%$ ) from Baker, $\mathrm{Si}(\mathrm{OEt})_{4}$ (TEOS) from Fluka, and anhydrous ammonia gas $(99.98 \%$ ) from Messer Austria GmbH. All Chemicals were used as received. The carbon spheres were prepared from an aqueous solution of glucose under hydrothermal conditions at $180^{\circ} \mathrm{C}$ according to the procedure reported by Sun et al. ${ }^{[10]}$

Materials Characterization: Thermogravimetric analysis (TGA) was performed with a Netzsch TG 209C Iris at a heating rate of $10^{\circ} \mathrm{C} /$ min under synthetic air. X-ray powder diffraction (XRD) measurements were performed with a PANalytical X'Pert PRO BraggBrentano X-ray powder diffractometer using $\mathrm{Cu}-K_{\alpha 1}$ radiation $(\lambda=$ $1.5406 \AA$ ). Scanning electron microscope (SEM) images and energy dispersive X-ray analysis (EDX) were obtained using a FEI QUANTA-200 SEM and transmission electron microscopy (TEM) as well as scanning transmission electron microscopy (STEM) images using a TECNAI F20-S-TWIN with field emission source operating at $200 \mathrm{kV}$. The powders were deposited on a carbon grid for TEM analysis.

Nitrogen sorption measurements at $77 \mathrm{~K}$ were carried out with a Micromeritics ASAP 2020. The samples were left standing in vacuo 
overnight at room temp. prior to measurement. The surface area was calculated according to Brunauer, Emmett, and Teller (BET) and the $t$-plot method, and the pore size distribution, pore diameters and pore volumes according to Barrett, Joyner, and Halenda (BJH) from the adsorption branch of the isotherm.

Preparation of $\mathbf{C u}_{3} \mathbf{N} @ \mathrm{SiO}_{2}(\mathbf{A})$ Spheres: Carbon spheres (200 mg) were dispersed in a $\mathrm{Cu}\left(\mathrm{NO}_{3}\right)_{2} \cdot 3 \mathrm{H}_{2} \mathrm{O}$ solution $(0.5 \mathrm{M}, 50 \mathrm{~mL})$ with ultra-sonication for $60 \mathrm{~min}$, followed by gentle stirring for $15 \mathrm{~h}$. The copper-loaded CS were washed several times with distilled water and separated by centrifugation and then dried at $80^{\circ} \mathrm{C}$ for $6 \mathrm{~h}$.

The copper-loaded CS $(175 \mathrm{mg})$ were dispersed in water $(25 \mathrm{~mL})$ with ultrasonication for $30 \mathrm{~min}$. CTAB $(0.28 \mathrm{~g})$ was dissolved in a mixture of water $(29 \mathrm{~mL})$ and ethanol $(22.2 \mathrm{~mL})$. Both solutions were then mixed with stirring, followed by addition of aq. ammonia $(25 \%, 0.9 \mathrm{~mL})$. After stirring for $30 \mathrm{~min}$ TEOS $(0.5 \mathrm{~mL})$ was added dropwise. The reaction mixture was stirred for $60 \mathrm{~h}$ at room temp. The CS/TEOS weight ratio was kept at 2.7, and the molar ratio of TEOS/CTAB/ $/ \mathrm{NH}_{3} / \mathrm{EtOH} / \mathrm{H}_{2} \mathrm{O}$ was $1: 0.34: 5.3: 168: 1320 . \mathrm{Cu}^{2+} / \mathrm{CS} /$ $\mathrm{SiO}_{2}$ was obtained by centrifugation, followed by three lots of washing and dispersion in water and finally drying at $80^{\circ} \mathrm{C}$. Heating at $550^{\circ} \mathrm{C}$ for $6 \mathrm{~h}$ in air gave $\mathrm{CuO} @ \mathrm{SiO}_{2}(\mathrm{~A})$ as a black powder.

The CuO@ $\mathrm{SiO}_{2}(\mathrm{~A})$ spheres were nitridated at $300{ }^{\circ} \mathrm{C}$ for $10 \mathrm{~h}$ in a horizontal tube furnace, under ammonia atmosphere with a flow rate of $10 \mathrm{~L} / \mathrm{h}$. The furnace was allowed to cool in an ammonia atmosphere, and a brown product was obtained.

Synthesis of $\mathrm{Cu}_{3} \mathrm{~N} @ \mathrm{SiO}_{2}(\mathrm{~B})$ Spheres: An aqueous ammonia solution was slowly added to $10 \mathrm{~mL}$ of a $0.5 \mathrm{~m}$ copper nitrate solution. Carbon spheres $(100 \mathrm{mg}$ ) were dispersed into the dark blue solution with ultrasonication for $30 \mathrm{~min}$ followed by gentle stirring for $15 \mathrm{~h}$. The CS loaded with $\left[\mathrm{Cu}\left(\mathrm{NH}_{3}\right)_{4}\left(\mathrm{H}_{2} \mathrm{O}\right)_{2}\right]^{2+}$ were washed several times with distilled water and separated by centrifugation and then dried at $80^{\circ} \mathrm{C}$ for $6 \mathrm{~h}$.

The $\left[\mathrm{Cu}\left(\mathrm{NH}_{3}\right)_{4}\left(\mathrm{H}_{2} \mathrm{O}\right)_{2}\right]^{2+}$-loaded $\mathrm{CS}(100 \mathrm{mg})$ were dispersed in water $(10 \mathrm{~mL})$ with ultrasonication for $30 \mathrm{~min}$. CTAB $(0.12 \mathrm{~g})$ was dissolved in a mixture of water $(13 \mathrm{~mL})$ and ethanol $(10 \mathrm{~mL})$. Both solutions were mixed with stirring followed by addition of aq. ammonia $(25 \%, 0.38 \mathrm{~mL})$. The mixture was stirred for $30 \mathrm{~min}$, and finally $0.21 \mathrm{~mL}$ of TEOS was added dropwise. The reaction was stirred for $60 \mathrm{~h}$ at room temp. The weight ratio of $\left[\mathrm{Cu}\left(\mathrm{NH}_{3}\right)_{4}\right.$ $\left.\left(\mathrm{H}_{2} \mathrm{O}\right)_{2}\right]^{2+} / \mathrm{CS}$ to TEOS was 2. The molar ratio of TEOS/CTAB/ $\mathrm{NH}_{3} / \mathrm{EtOH} / \mathrm{H}_{2} \mathrm{O}$ was 1:0.34:5.3:168:1320. $\left[\mathrm{Cu}\left(\mathrm{NH}_{3}\right)_{4}\left(\mathrm{H}_{2} \mathrm{O}\right)_{2}\right]^{2+} / \mathrm{CS} /$ $\mathrm{SiO}_{2}$ was obtained by centrifugation followed by three lots of washing and dispersion in water and finally drying at $80^{\circ} \mathrm{C}$. Heating at $500{ }^{\circ} \mathrm{C}$ for $2 \mathrm{~h}$ in air gave $\mathrm{CuO} @ \mathrm{SiO}_{2}(\mathrm{~B})$ as a black powder.

The $\mathrm{CuO} @ \mathrm{SiO}_{2}$ (B) spheres were nitridated at $350{ }^{\circ} \mathrm{C}$ for $2 \mathrm{~h}$ under ammonia with a flow rate of $15 \mathrm{~L} / \mathrm{h}$. The furnace was allowed to cool in ammonia atmosphere, and a brown product was obtained.

Synthesis of Stöber Particles: A solution of $81 \mathrm{~mL}$ of ethanol and $24.5 \mathrm{~mL}$ of $\mathrm{NH}_{3}(28-30 \%)$ was stirred with $750 \mathrm{rpm}$ at $30{ }^{\circ} \mathrm{C}$ in a $500-\mathrm{mL}$ round-bottomed flask sealed with a septum. TEOS $(4.2 \mathrm{~mL})$ was injected rapidly into this solution, and the reaction was stirred for $60 \mathrm{~min}$. A colloidal suspension of silica spheres was obtained, which was centrifuged and washed with ethanol and water several times. The white solid was dried at $60^{\circ} \mathrm{C}$ for $6 \mathrm{~h}$.

Synthesis of Hollow $\mathrm{CuSiO}_{3}$ Spheres: In a typical experiment, $\mathrm{SiO}_{2}$ spheres $(0.130 \mathrm{~g})$ were dispersed in distilled water $(30 \mathrm{~mL})$ using ultrasonication. $\mathrm{Cu}\left(\mathrm{NO}_{3}\right) \cdot 3 \mathrm{H}_{2} \mathrm{O}(0.7 \mathrm{mmol})$ was separately dissolved in distilled water $(30 \mathrm{~mL})$ followed by addition of aq. ammonia $(30 \%, 3 \mathrm{~mL})$. The homogeneous solution obtained after mixing the two solutions was transferred into an 80 -mL Teflon-lined stainless steel autoclave. The autoclave was kept at $140{ }^{\circ} \mathrm{C}$ for $24 \mathrm{~h}$ in a preheated electric oven and was then allowed to cool to room temp. A blue product was isolated by centrifugation and was washed several times with water, followed by drying at $70^{\circ} \mathrm{C}$ for $6 \mathrm{~h}$.

Synthesis of $\mathrm{CuO}$ on $\mathrm{SiO}_{2}$ : The hollow $\mathrm{CuSiO}_{3}$ spheres were placed in a ceramic boat. The boat was kept in a horizontal tube furnace at $700{ }^{\circ} \mathrm{C}$ for $30 \mathrm{~min}$ in air with a heating rate of $3{ }^{\circ} \mathrm{C} / \mathrm{min}$. Black $\mathrm{CuO}$ on $\mathrm{SiO}_{2}$ was obtained.

Synthesis of $\mathrm{Cu}_{3} \mathbf{N}$ on $\mathrm{SiO}_{2}$ : The hollow $\mathrm{CuSiO}_{3}$ spheres were placed in a ceramic boat. The boat was kept in a horizontal tube furnace at $350{ }^{\circ} \mathrm{C}$ for $1 \mathrm{~h}$ in ammonia atmosphere with a heating rate of $3{ }^{\circ} \mathrm{C} / \mathrm{min}$. The $\mathrm{NH}_{3}$ flow rate was maintained at $10 \mathrm{~L} / \mathrm{h}$. Brown $\mathrm{Cu}_{3} \mathrm{~N}$ on $\mathrm{SiO}_{2}$ was obtained.

Supporting Information (see footnote on the first page of this article): TGA analysis of $\mathrm{Cu}^{2+} / \mathrm{CS} / \mathrm{SiO}_{2} /$ and $\left[\mathrm{Cu}\left(\mathrm{NH}_{3}\right)_{4}\left(\mathrm{H}_{2} \mathrm{O}\right)_{2}\right]^{2+} /$ $\mathrm{CS} / \mathrm{SiO}_{2}$ composite spheres, $\mathrm{N}_{2}$ adsorption and desorption isotherms of $\mathrm{CuO} @ \mathrm{SiO}_{2}(\mathrm{~A}), \mathrm{CuO} @ \mathrm{SiO}_{2}(\mathrm{~B}), \mathrm{Cu}_{3} \mathrm{~N} @ \mathrm{SiO}_{2}(\mathrm{~A})$, $\mathrm{Cu}_{3} \mathrm{~N} @ \mathrm{SiO}_{2}(\mathrm{~B}), \mathrm{CuO}$ on $\mathrm{SiO}_{2}, \mathrm{Cu}_{3} \mathrm{~N}$ on $\mathrm{SiO}_{2}, \mathrm{SEM}$ images of $\mathrm{Cu}_{3} \mathrm{~N} @ \mathrm{SiO}_{2}(\mathrm{~A}), \mathrm{CuO} @ \mathrm{SiO}_{2}(\mathrm{~B}), \mathrm{Cu}_{3} \mathrm{~N}$ on $\mathrm{SiO}_{2}, \mathrm{EDX}$ spectra of $\mathrm{Cu}_{3} \mathrm{~N} @ \mathrm{SiO}_{2}(\mathrm{~A}), \mathrm{Cu}_{3} \mathrm{~N} @ \mathrm{SiO}_{2}(\mathrm{~B})$, and XRD pattern of $\mathrm{CuSiO}_{3}$ spheres.

\section{Acknowledgments}

This work was supported by the Austrian Science Funds (FWF) (project number P20750) and Vienna University of Technology (Doctoral School on Functional Materials). The authors thank E. Eitenberger for SEM, J. Bernardi for TEM, and E. Halwax for XRD measurements.

[1] a) Y. Zhao, L. Jiang, Adv. Mater. 2009, 21, 3621-3638 b) H. C. Zeng, J. Mater. Chem. 2011, 21, 7511-7526; c) X. W. Lou, L. A. Archer, Z. C. Yang, Adv. Mater. 2008, 20, 3987-4019; d) J. Hu, M. Chen, X. S. Fang, L. W. Wu, Chem. Soc. Rev. 2011, 40, 5472-5491; e) X. Y. Lai, J. E. Halpert, D. Wang, Energy Environ. Sci. 2012, 5, 5604-5618.

[2] For a review article on hollow silica nanospheres, see: X. Li, Y. Yang, Q. Yang, J. Mater. Chem. A 2013, 1, 1525-1535.

[3] For an example, see: a) X. F. Zhai, M. Yu, Z. Y. Cheng, Z. Y. Hou, P. A. Ma, D. M. Yang, X. J. Kang, Y. L. Dai, D. Wang, J. Lin, Dalton Trans. 2011, 40, 12818-12825; b) D. P. Wang, H. C. Zeng, Chem. Mater. 2011, 23, 4886-4899; c) Y. Yamada, M. Mizutani, T. Nakamura, K. Yano, Chem. Mater. 2010, 22, 1695-1703.

[4] a) J. C. Park, H. Song, Nano Res. 2011, 4, 33-49; b) J. C. Park, H. J. Lee, J. Y. Kim, K. H. Park, H. Song, J. Phys. Chem. C 2010, 114, 6381-6388; c) K. X. Yao, H. C. Zeng, Chem. Mater. 2012, 24, 140-148; d) J. C. Park, E. Heo, A. Kim, M. Kim, K. H. Park, H. Song, J. Phys. Chem. C 2011, 115, 1577215777.

[5] Z. Chen, Z. M. Cui, F. Niu, L. Jiang, W. G. Song, Chem. Commun. 2010, 46, 6524-6526.

[6] Y. F. Zhu, E. Kockrick, T. Ikoma, N. Hanagata, S. Kaskel, Chem. Mater. 2009, 21, 2547-2553.

[7] R. Deshmukh, U. Schubert, J. Mater. Chem. 2011, 21, 18534 18536.

[8] a) B. S. Lee, M. Yi, S. Y. Chu, J. Y. Lee, H. R. Kwon, K. R. Lee, D. Kang, W. S. Kim, H. Bin Lim, J. Lee, H. J. Youn, D. Y. Chi, N. H. Hur, Chem. Commun. 2010, 46, 3935-3937; b) F. Zaccheria, F. Santoro, R. Psaro, N. Ravasio, Green Chem. 2011, 13, 545-548; c) Z. Y. Wang, Q. S. Lu, P. Y. Wang, J. G. Li, J. Exp. Nanosci. 2011, 6, 528-538; d) J. Yu, X. H. Ma, M.Z. Wang, C. J. Yu, T. Bai, Appl. Surf. Sci. 2008, 254, 5089-5094; e) A. P. L. Batista, H. W. P. Carvalho, G. H. P. Luz, P. F. Q. 
Martins, M. Goncalves, L. C. A. Oliveira, Environ. Chem. Lett. 2010, 8, 63-67.

[9] For an example, see: a) X. M. Sun, J. F. Liu, Y. D. Li, Chem. Eur. J. 2006, 12, 2039-2047; b) X. Wang, P. Hu, F. L. Yuan, L. J. Yu, J. Phys. Chem. C 2007, 111, 6706-6712; c) F. He, P. P. Yang, D. Wang, C. X. Li, N. Niu, S. L. Gai, M. L. Zhang, Langmuir 2011, 27, 5616-5623; d) X. M. Sun, Y. D. Li, Angew. Chem. 2004, 116, 3915; Angew. Chem. Int. Ed. 2004, 43, 38273831.

[10] X. M. Sun, Y. D. Li, Angew. Chem. 2004, 116, 607; Angew. Chem. Int. Ed. 2004, 43, 597-601.
[11] P. Jin, Q. W. Chen, L. Q. Hao, R. F. Tian, L. X. Zhang, L. Wang, J. Phys. Chem. B 2004, 108, 6311-6314.

[12] W. Stöber, A. Fink, E. Bohn, J. Colloid Interface Sci. 1968, 26, 62-69.

[13] Y. Q. Wang, G. Z. Wang, H. Q. Wang, W. P. Cai, L. D. Zhang, Chem. Commun. 2008, 6555-6557.

[14] X. Li, V. T. John, G. He, L. Spinu, J. Mater. Chem. 2012, 22, 17476-17484.

Received: November 28, 2012

Published Online: March 8, 2013 